Tahun XI, No. 20, April 2015

\title{
PENGARUH MODEL KOPERATIF TIPE STAD DAN NHT TERHADAP PRESTASI BELAJAR MAHASISWA PGSD UNIPA SURABAYA PADA MATERI SISTEM PEREKONOMIAN INDONESIA
}

\author{
Danang Prastyo \\ Dosen Program Studi PGSD - FKIP - Universitas PGRI Adibuana (Unipa) Surabaya
}

\begin{abstract}
The purpose of this study is to find out the effectiveness of cooperative learning type numbered heads together (NHT) and Student Teams Achievement Divisions (STAD) application on student learning outcomes in cooperative materials in the Unipa University. In addition this study aims to determine the differences between the student learning outcomes by NHT, STAD cooperative learning type and the student learning outcomes by conventional learning in the Indonesia econmy system in the Unipa University.

The study applies random sampling. The research population is students in the Unipa University. While the sample of this research is fourth-grade students who are divided into three classes namely trials class D, experimental class A and D, control class A.

The validity used is the content and construct validation. Reliability in this study is tested by applying KR-20 techniques. Data analysis is performed using aid of statistical program SPSS version 17 for windows.

By analyzing research data, it is obtained that the difference is as amount 0.000. This shows that there are actually the differences between the experimental class and the control class after the treatment of NHT and STAD learning type given. That is, the learning type NHT and STAD is proven effectively for improving students' abilities in comprehending the Indonesia econmy system.
\end{abstract}

Keyword: Numbered Heads Together, Student Teams Achievement Divisions (STAD, Student learning outcomes

\section{PENDAHULUAN}

Sebagai lembaga pencetak pendidikan, keberadaan perguruan tinggi (PT) dituntut untuk dapat menghasilkan lulusan yang berkualitas. Berbagai upaya telah dilakukan PT mulai dari perbaikan sarana dan prasarana hingga peningkatan kualitas pengajaran pendidiknya, tujuannya tidak lain untuk menghasilkan lulusan yang berkualitas. Banyaknya anggaran yang dikucurkan pihak pengelola terkadang tidak sebanding dengan peningkatan kualitas lulusannya.

Dari pengamatan peneliti banyak model pembelajaran yang diterapkan dosen di kelas sehingga hasil yang diharapkan oleh pendidik tidak maksimal. Jika dilihat sampai saat ini masih ditemukan sebagian pendidik melakukan proses belajar mengajar Ilmu Pengetahuan Sosial (IPS) dengan menggunakan model pembelajaran seadanya, sehingga berakibat tidak tercapainya hasil belajar yang maksimal. Pendidik yang baik adalah sesorang yang mampu menerapkan model pembelajaran sesuai dengan hasil dan tujuan pembelajaran. Banyaknya model pembelajaran yang ada tidak akan berpengaruh terhadap hasil belajar jika pendidik tidak cermat dan tepat dalam menerapkannya model pembelajaran.

Dari kasus yang ditemukan di lapangan, pembelajaran IPS yang terjadi di Jurusan PGSD Unipa Surabaya terkesan monoton, akibatnya peserta didik lebih banyak diam dan menerima pengetahuan apa adanya tanpa ada pertanyaan kritis dari peserta didik. Selain itu dari beberapa diskusi dengan rekan pendidik sejawat dari Unipa masih ditemukan dosen yang mengajar dengan model pembelajaran lama atau tradisional.

Sebagai tenaga pengajar, pendidik berperan penting dalam meningkatkan prestasi belajar peserta didik. Banyak cara yang dapat digunakan pendidik agar prestasi belajar peserta didik meningkat, salah satunya dengan cara memilih model pembelajaran koperatif. Dari banyaknya model pembelajaran 
kooperatif yang ada diharapkan pendidik dapat memilih salah satu model pembelajaran yang menurut pendidik sangat tepat dalam mencapai tujuan pembelajaran. Model pembejaran koperatif tipe Student Teams Achievement Divisions (STAD) dan Numbered Head Together (NHT) dipilih karena model pembelajaran ini sangat mudah dilakukan dan dinilai efektif dalam meningkatkan prestasi belajar peserta didik.

Dari beberapa masalah yang ditemukan di lapangan maka peneliti merasa tertarik untuk melakukan penelitian dengan judul "Pengaruh Model Koperatif Tipe STAD dan NHT Terhadap Prestasi Belajar Mahasiswa PGSD Unipa Surabaya pada Materi Sistem Perekonomian Indonesia,'.

\section{Rumusan Masalah}

1. Bagaimana pelaksanaan pembelajaran koperatif tipe NHT dan STAD terhadap hasil belajar mahasiswa pada materi Sistem Perekonomian Indonesia di PGSD Unipa Surabaya?

2. Adakah perbedaan hasil belajar pada materi Sistem Perekonomian Indonesia dengan menggunakan metode pembelajaran koperatif tipe NHT dan STAD?

\section{Tujuan Penelitian}

1. Mengetahui pelaksanaan pembelajaran koopertif tipe NHT dan STAD terhadap hasil belajar mahasiswa dalam materi Konsep Sistem Perekonomian Indonesia di PGSD Unipa Surabaya.

2. Mengetahui perbedaan hasil belajar pada materi Sistem Perekonomian Indonesia dengan menggunakan metode pembelajaran koperatif tipe NHT dan STAD.

\section{KAJIAN PUSTAKA}

\section{Pembelajaran Koperatif}

Menurut Slavin (dalam Isjoni, 2007:15),

''In Cooperative learning methods, students work together in faur,". Artinya cooperative learning adalah suatu model pembelajaran atau sistem belajar yang bekerja dalam kelompok-kelompok kecil dengan berjumlah 4-6 orang secara kolaboratif, sehingga dapat merangsang peserta didik untuk bersemangat dalam belajar.
Menurut Muslimin (2005:3) model pembelajaran koperatif "menuntut kerjasama peserta didik dan saling ketergantungan dalam struktur tugas, tujuan dan hadiah". Sedangkan pembelajaran koperatif adalah mengajarkan sesuatu secara bersama-sama dengan saling membantu satu sama lainnya sebagai satu tim (Isjoni, 2007:6).

Dari uraian di atas dapat disimpulkan bahwa model pembelajaran koperatif merupakan suatu model pembelajaran dalam kelompok kecil yang memiliki tingkat kemampuan berbeda-beda dan saling bergantung satu sama lain untuk menyelesaikan tugas dalam mencapai tujuan bersama.

\section{Ciri-ciri Pembelajaran Koperatif}

Menurut Isjoni (2007:20) ciri-ciri dalam pembelajaran koperatif adalah

a) Terjadi hubungan interaksi langusung diantara peserta didik .

b) Setiap anggota memiliki peran.

c) Setiap anggota kelompok bertanggung jawab atas belajarnya dan juga teman-teman sekelompoknya.

d) Pendidik membantu mengembangkan ketrampilan-ketrampilan interpersonal kelompok.

e) Pendidik hanya berinteraksi dengan kelompok apabila diperlukan.

Jadi dapat disimpulkan bahwa ciri-ciri pembelajaran koperatif meliputi adanya kerjasama dengan kelompok, tanggung jawab pada kelompok, peranan pendidik tidak dominan dan adanya penghargaan kepada kelompok.

\section{Tujuan Pembelajaran Koperatif}

Menurut Sharan (dalam Isjoni, 2007:23) menyebutkan, tujuan pembelajaran koperatif sebagai berikut:

a) Menghasilkan peningkatan kemampuan akademik.

b) Meningkatkan kemampuan berpikir kritis.

c) Membentuk hubungan persahabatan.

d) Menimba berbagai informasi.

e) Belajar menggunakan sopan santun.

f) Meningkatkan motivasi peserta didik .

g) Memperbaiki sekap terhadap sekolah. 
h) Belajar mengurangi tingkah laku yang kurang baik.

i) Membantu peserta didik dalam menghargai pokok pikiran orang lain.

Dari uraian di atas dapat disimpulkan bahwa tujuan pembelajaran koperatif agar peserta didik dapat berkelompok dengan teman-temannya. Selain itu dapat menumbuhkan rasa saling menghargai pendapat peserta lain untuk mengemukakan pendapatnya.

\section{Pembelajaran STAD}

Pembelajaran tipe STAD merupakan salah satu tipe yang paling sederhana dalam model pembelajaran koperatif. Menurut Slavin (1995:71) STAD is one of the simples of all cooperative learning methods and is a good model to begin with for teachers who are new to the cooperative approach. STAD merupakan model yang tepat untuk para guru, dosen dan peneliti yang masih baru dalam menggunakan model koperatif.

Pada STAD, siswa dibagi dalam tim belajar yang terdiri dari empat orang yang berbeda-beda berdasarkan tingkat kemampuan, jenis kelamin dan latar belakang etniknya. Guru menyampaikan pelajaran lalu siswa bekerja dalam tim mereka untuk memastikan bahwa semua tim telah menguasai pelajaran. Selanjutnya, semua siswa mengerjakan kuis mengenai ,ateri secara sendiri-sendiri, dimana pada saat itu mereka tidak diperbolehkan untuk saling bantu. Menurut Nur (2005:23) mengatakan, sebuah tim dalam STAD merupakan sebuah kelompok terdiri dari empat atau lima siswa yang mewakili heterogenitas kelas ditinjau dari kinerja masa lalu, suku dan jenis kelamin. Tim empat orang yang didalamnya terdiri atas dua orang lakilaki dan dua perempuan terdiri dari atas satu orang dengan kinerja tinggi, dua orang kinerja rata-rata dan satu orang kinerja rendah. Bila dimungkinkan tiga orang berasal dari suku mayoritas dan satu orang dari suku minoritas.

\section{Langkah Pembelajaran STAD}

Menurut Huda (2014:202) ada beberapa empat tahapan yang harus dilakukan dalam menerapkan model pembelajaran STAD diantaranya adalah pengajaran, tim studi, tes, rekognisi. Untuk penjelasannya sebagai berikut yaitu:

Tahap 1 Pengajaran

Pada tahap ini, guru menyajikan materi pelajaran, biasanya dengan format ceramah atau diskusi. Padan tahap pengajaran siswa seharusnya diajarkan tentang apa yang akan mereka pelajari dan mengapa pelajaran tersebut penting.

Tahap 2 Tim Studi

Pada tahap ini para anggota kelompok bekerja secara kooperatif untuk menyelesaikan lembar kerja dan lembar jawaban yang telah disediakan oleh guru.

Tahap 3: Tes

Pada tahap ujian, setiap siswa secara individual menyelesaikan kuis. Guru menscore kuis tersebut dan mencatat pemerolehan hasilnya saat itu secara hasil kuis pada pertemuan sebelumnya. Hasil dari tes individu akan diakumulasikan untuk skor tim mereka.

Tahap 4: Rekognisi

Setiap tim menerima penghargaan atau reward bergantung pada nilai skor rata-rata tim.

\section{Pembelajaran Numbered Heads Together (NHT)}

Menurut Muslimin (2005:28) ada beberapa langkah yang harus dilakukan dalam pembelajaran Numbered-Heads-Together (NHT), antara lain:

Langkah-1 : Numbering (penomoran). Guru membagi siswa ke dalam kelompok beranggotakan 5 orang dan kepada setiap anggota kelompok diberi nomor 1 sampai 5.

Langkah-2 : Questioning (mengajukan pertanyaan). Guru mengajukan sebuah pertanyaan kepada siswa.

Langkah-3 : Heads together (berfikir bersama). Siswa menyatukan pendapatnya terhadap jawaban pertanyaan dan meyakinkan tiap anggoata dalam timnya untuk mengetahui jawabannya.

Langkah-4 : Answering (menjawab). Guru memanggil suatu nomor tertentu, kemudian siswa yang nomornya sesuai mengacungkan tangan dan mencoba untuk menjawab 
pertayaan untuk seluruh kelas. (Muslimin, 2005:28).

\section{Pembelajaran Konvensional}

Pembelajaran konvensional merupakan proses pembelajaran yang dilakukan pendidik dengan cara menerapkan metode ceramah dan pendidik cenderung dominan dari pada peserta didik. Pada penerapan pembelajaran konvensional di kelas akan berdampak terhadap dua hal yaitu kelebihan dan kelemahan.

Kelebihan pembelajaran konvensional antara lain sebagai berikut:

a) Setiap peserta didik memiliki kesempatan yang sama untuk mendengarkan penjelasan guru.

b) Isi silabus dapat diselesaikan dengan mudah karena tidak harus menyesuaikan dengan kemampuan pendidik sebab bahan pelajaran telah disusun secara urut.

Sedangkan kelemahan pembelajaran konvensional antara lain sebagai berikut:

a) Pelajaran berjalan membosankan.

b) Peserta didik menjadi pasif dan hanya menulis saja.

c) Peserta didik hanya belajar menghafal tanpa pemahaman.

\section{Hipotesis}

Hipotesis penilitian ini adalah ada perbedaan hasil belajar dalam model pembelajaran NHT, STAD dan konvensional pada pokok bahasan Sistem Perekonomian Indonesia.

\section{METODOLOGI PENELITIAN}

\section{Rancangan Penelitian}

Pada penelitian ini peneliti menggunakan penelitian eksperimen. Penelitian eksperimen dilakukan karena peneliti akan mengujicobakan penelitiaanya ke dalam tiga kelas, yaitu dengan menerapkan model pembelajaran STAD, model pembelajaran NHT dan model pembelajaran konvensional.

\section{Prosedur Penelitian}

Prosedur dalam penelitian ini terdiri dari empat tahap yaitu persiapan, pelaksanaan, analisis data dan penulisan laporan. Untuk masing-masing pelaksanaannya akan dipaparkan sebagai berikut:

a. Tahap Persiapan

Pada tahap persiapan peneliti akan melakukan beberapa langkah diantaranya adalah

a. Menentukan populasi dan sampel penelitian.

b. Membuat perangkat pembelajaran.

c.Menganalisis hasil uji coba perangkat pembelajaran dengan tujuan untuk merevisi perangkat yang ada.

2. Tahap Pelaksanaan

Untuk tahap pelaksanaan peneliti akan melakukan beberapa langkah diantaranya adalah

a. Memberikan pretes kepada tiga kelas.b.Melaksanakan pembelajaran koperatif di dua kelas dengan menggunakan model NHT dan model STAD.

c. Memberikan posttest untuk kelas STAD, NHT dan konvensional.

3. Tahap Analisis Data

Pada tahapan ini peneliti akan menganalis dan menyimpulkan hasil dari penelitiannya.

4. Tahap Penulisan Laporan

Tahapan penulisan laporan dilakukan setelah peneliti menghasilkan sebuah hasil dari penelitiannya.

\section{Sampel Penelitian}

Uji coba dilaksanakan pada Jurusan PGSD Unipa tahun 2014 dengan memilih satu kelas secara acak dari empat kelas paralel yang berkemampuan setara. Untuk mengetahui kemampuan peserta didik agar setara peneliti meminta saran dari ketua program studi atau pendidik yang bersangkutan.

\section{Instrumen Penelitian Uji Coba}

Dalam rangka mengumpulkan data uji coba, peneliti membuat instrumen THB dikembangkan sendiri oleh peneliti. Tes dalam penelitian ini berupa tes pilihan ganda. THB diberikan kepada peserta didik sebanyak dua kali yaitu sebelum dan sesudah dimulai pokok bahasan Sistem Perekonomian Indonesia. Tujuan dilakukanya tes dimaksudkan untuk mengetahui perbedaan hasil belajar peserta didik sebelum dan sesudah pembelajaran. 


\section{Uji Validitas dan Reliabilitas Perangkat Pembelajaran}

\section{Uji Validitas}

Uji validitas dilakukan untuk menguji apakah perangkat penelitian ini telah mengukur apa yang seharusnya diukur. Untuk menguji agar tes hasil belajar (THB) valid, peneliti melakukan analisis validasi butir soal. Validitas item (butir soal) dihitung untuk mengetahui seberapa jauh hubungan antara jawaban suatu butir soal dengan skor total yang telah ditetapkan

\section{Uji Reliabilitas Tes Hasil Belajar (THB)}

Uji reliabilitas dilakukan untuk menguji keajegan atau konsistensi perangkat pembelajaran. Dalam penelitian ini, uji reliabilitas meliputi: tes hasil belajar (THB).

\section{Rancangan Penelitian}

Peneltian ini menggunakan desain Randomized Control Group Pretest-Postest Desaing. Desain ini dinilai mendekati sempurna mengingat ada kelompok kontrol, ada perlakukan, subjek ditempatkan secara acak dan adanya pretest dan posttes untuk memastikan efektiviatas perlakuan yang diberikan. (Maksum, 2009: 49).

Tabel 3.2 Rancangan Eksperimen

\begin{tabular}{|l|r|c|c||}
\hline Kelompok & Pretes & Perlakuan & Postest \\
\hline Eksperimen 1 & T1 & X1 & T2 \\
Eksperimen 2 & T1 & X2 & T2 \\
Kontrol & T1 & X & T2 \\
\hline
\end{tabular}

Keterangan :

$\mathrm{X} 1$ = Perlakuan model STAD

$\mathrm{X} 2$ = Perlakuan model NHT

$\mathrm{X}=$ Konvesional

$\mathrm{T} 1$ = Pretest kelompok Eksperimen 1,2 dan kelompok kontrol

$\mathrm{T} 2=$ Post-test kelompok Eksperimen 1,2 dan kelompok kontrol.

\section{Teknik Analisis Data Eksperimen}

Pada penelitian ini digunakan dua teknik analisis data, yaitu analisis statistik deskriptif dan analisis statistik inferensial. Sedangkan untuk uji beda yang dipakai dalam penelitian ini adalah uji-t. Penghitungan uji-t dilakukan dengan bantuan program SPSS versi 17.0 for windows.

\section{HASIL PENELITIAN}

\section{Hasil Uji Homogenitas dan Normalitas}

Sebelum melakukan penelitian, terlebih dahulu peneliti menguji homogenitas dan normalitas mahasiswa PGSD Unipa Surabaya pada angkatan 2014 kelas A, kelas B dan kelas D.

Dari tabel deskriptif diatas dapat disimpulkan bahwa jumlah mahasiswa pada kelas A sebanyak 40 orang dan kelas B sebanyak 39 orang. Sedangkan pada kelas D berjumlah 38 orang. Nilai minimum yang diperoleh kelas A sebesar 60 dan kelas B sebesar 55, sedangkan pada kelas D sebesar 50. Nilai maksimum yang diperoleh kelas A sebesar 87 dan kelas B sebesar 90, sedangkan pada kelas D sebesar 90. Nilai rata-rata pada kelas A sebesar 76.35, pada kelas B sebesar 72.56, dan pada kelas D sebesar 73.94. Besaran standar deviasi pada kelas A adalah 6.59662, kelas B 9.79203 dan kelas D 10.60073 .

\section{Hasil validitas dan Realibilitas}

Dari data pada tabel estimasi parameter diribusi menunjukkan bahwa ketiga kelas tersebut berada dalam distribusi normal. Perinciannya sebagai berikut, nilai pada kelas A sebesar 76.35 dalam skala 6.59662, untuk kelas B nilainya sebesar 72.56 dalam skala 9.79203, dan kelas D nilainya sebesar 73.94 
dalam skala 10.60073. Sehingga kesimpulannya, ketiga kelas tersebut homogen, artinya siswa pada kelas A, kelas B dan kelas D memiliki kemampuan yang sama. Penjelasan homogenitas ini juga dapat dilihat pada grafik masing-masing kelas dibawah ini. Dalam tiap grafik tampak data di kelas A, B dan $\mathrm{D}$ mengumpul pada sekitar garis, tidak menyebar, sehingga datanya dapat dikatakan homogen.

\section{Grafik}
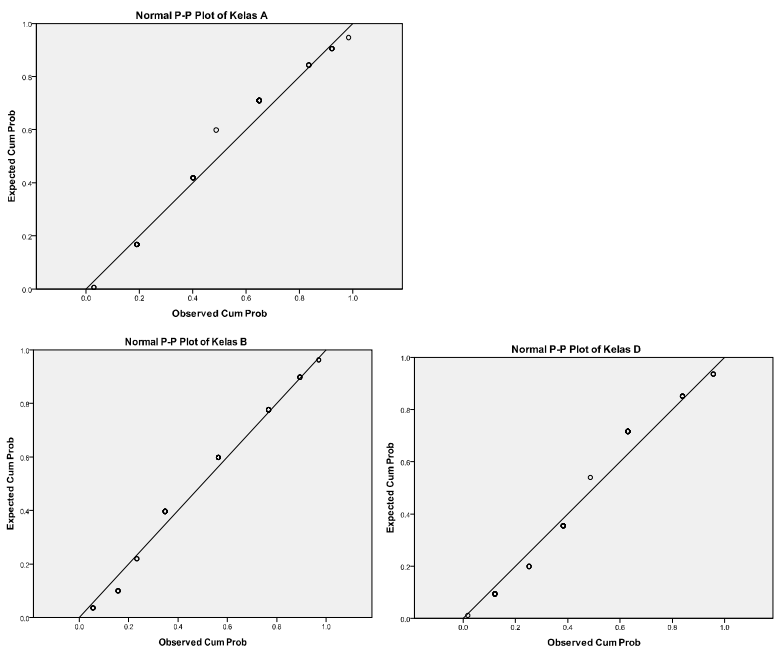

Ujicoba tes hasil belajar dilakukan untuk mendapatkan data mengenai validitas butir tes dan reliabilitas tes. Untuk menentukan butir soal yang valid maka dilakukan perbandingan antara $r_{x y}$ hitung dengan $r$ tabel ( $\mathrm{r}$ tabel ditentukan dari dari tabel $\mathrm{r}$ dengan melihat nilai signifikansi 5\% dan sesuai dengan jumlah subjek penelitian). Jika $r_{x y}$ lebih besar dari $r$ tabel, maka butir soal tersebut dapat dinyatakan valid. Dan sebaliknya, Jika $r_{x y}$ lebih kecil dari $r$ tabel, maka butir soal tersebut dapat dinyatakan tidak valid. Nilai $r$ tabel dalam penelitian ini adalah 0,404 (untuk signifikansi sebesar 5\%, dan jumlah subjek penelitian sejumlah 24).

Berdasarkan data pada tabel di atas, dapat disimpulkan bahwa hanya terdapat 20 soal yang valid dari 30 soal.

\section{Hasil Reliabilitas Perangkat Uji Coba}

Berdasarkan hasil reliabilitas (pada lampiran) tes hasil belajar (THB) untuk 20 aitem terpilih terbesar 0,846 . Koefesien 0,846 lebih besar dari $r$ tabel $(0,404)$. Sehingga dapat disimpulkan perangkat THB reliabel.
1. Deskripsi
Data
Hasil
Penelitian Eksperimen

Hasil penelitian yang akan dianalisis secara deskriptif adalah hasil belajar mahasiswa. Hasil belajar yang ditunjukkan oleh nilai pretest dan postes pada kelas eksperimen dan kelas kontrol adalah sebagai berikut :

Tabel 4. 10

Nilai Tes Hasil Belajar

Descriptive Statistics

\begin{tabular}{|c|c|c|c|c|c|c|}
\hline & $\mathrm{N}$ & Minimum & Maximum & \multicolumn{2}{|c|}{ Mean } & Std. Deviation \\
\hline & Statistic & Statistic & Statistic & Statistic & Std. Error & Statistic \\
\hline $\begin{array}{l}\text { Pre Test STAD } \\
\text { Pre Test Konvensional } \\
\text { Pre Test NHT } \\
\text { Valid N (listwise) }\end{array}$ & $\begin{array}{l}42 \\
44 \\
38 \\
38\end{array}$ & $\begin{array}{l}40.00 \\
40.00 \\
40.00\end{array}$ & $\begin{array}{l}65.00 \\
60.00 \\
60.00\end{array}$ & $\begin{array}{l}48.4524 \\
47.1591 \\
49.8684\end{array}$ & $\begin{array}{r}1.08426 \\
.78634 \\
.89425\end{array}$ & $\begin{array}{l}7.02679 \\
5.21600 \\
5.51250\end{array}$ \\
\hline \multicolumn{7}{|c|}{ Descriptive Statistics } \\
\hline & $\mathrm{N}$ & Minimum & Maximum & \multicolumn{2}{|c|}{ Mean } & Std. Deviation \\
\hline & Statistic & Statistic & Statistic & Statistic & Std. Error & Statistic \\
\hline $\begin{array}{l}\text { Post Test STAD } \\
\text { Post Test Konvensional } \\
\text { Post Test NHT } \\
\text { Valid N (listwise) }\end{array}$ & $\begin{array}{l}42 \\
44 \\
38 \\
38\end{array}$ & $\begin{array}{l}40.00 \\
45.00 \\
55.00\end{array}$ & $\begin{array}{l}95.00 \\
90.00 \\
90.00\end{array}$ & $\begin{array}{l}62.7381 \\
73.6364 \\
78.8158\end{array}$ & $\begin{array}{l}2.19678 \\
1.93283 \\
1.64868\end{array}$ & $\begin{array}{l}14.23678 \\
12.82093 \\
10.16314\end{array}$ \\
\hline
\end{tabular}

Berdasarkan tabel di atas dapat disimpulkan bahwa jumlah peserta yang mengikuti pretest dimasing-masing kelas sebagai berikut: kelas A menggunakan model pembelajaran STAD berjumlah 42 siswa. Nilai minimum pretes kelas A sebesar 40 sedangkan 
nilai maksimumnya sebesar 65. Kelas B menggunakan model pembelajaran konvensional berjumlah 44 siswa. Nilai minimum pretes kelas A sebesar 40 sedangkan nilai maksimumnya sebesar 60. Kelas D menggunakan model pembelajaran NHT berjumlah 38 siswa. Nilai minimum pretes kelas A sebesar 40 sedangkan nilai maksimumnya sebesar 60. Untuk rata-rata nilai pada pretest di masing-masing kelas yaitu kelas A sebesar 48.45, kelas B sebesar 47.16, kelas D sebesar 49.87.

Sementara itu untuk jumlah peserta yang mengikuti posttest dimasing-masing kelas sebagai berikut: kelas A menggunakan model pembelajaran STAD berjumlah 42 siswa. Nilai minimum pretes kelas A sebesar 40 sedangkan nilai maksimumnya sebesar 95 . Kelas B menggunakan model pembelajaran konvensional berjumlah 44 siswa. Nilai minimum pretes kelas A sebesar 45 sedangkan nilai maksimumnya sebesar 90 . Kelas D menggunakan model pembelajaran NHT berjumlah 38 siswa. Nilai minimum pretes kelas A sebesar 55 sedangkan nilai maksimumnya sebesar 90. Untuk rata-rata nilai pada posttest di masing-masing kelas yaitu kelas A sebesar 62.74, kelas B sebesar 73.64, kelas D sebesar 78.82.

Selain itu pada tabel di atas menunjukkan ada peningkatan hasil belajar di masing-masing kelas. Pada kelas A rata-rata nilai pretest kelas A sebesar 48.45. kelas B rata-rata nilai pretest sebesar 47.16 , kelas $D$ rata-rata nilai pretest sebesar 49.87. Sedangkan pada kelas A rata-rata nilai posttest sebesar 62.74, kelas $\mathrm{B}$ rata-rata nilai posttest sebesar73.64 dan kelas $\mathrm{C}$ rata-rata nilai posttest sebesar 78.82 .

Dari uraian tersebut dapat disimpulkan bahwa dari tiga model pembelajaran yang diterapkan model NHT (Kelas C) memiliki nilai tertinggi jika dibandingkan dengan model pembelajaran STAD (Kelas A) dan konvesional (Kelas B).

\section{Analisis Statistik Parametrik a. Data deskriptif}

Tabel 4.11

Between-Subjects Factors

\begin{tabular}{|ll|l|r|}
\hline & & Value Label & $\mathrm{N}$ \\
\hline VAR00003 & 1.00 & STAD & 42 \\
& 2.00 & Konvensional & 44 \\
& 3.00 & NHT & 38 \\
\hline
\end{tabular}

Tabel ini menjelaskan bahwa variable fix factor ada 3 kelompok, yaitu peserta metode pembelajaran STAD berjumlah 42, peserta metode pembelajaran konvensional berjumlah 44 dan peserta metode pembelajaran NHT berjumlah 38 orang.

Tabel 4.11

Tests of Between-Subjects Effects

Dependent Variable:Post Test

\begin{tabular}{|l|r|r|r|r|r|r|}
\hline Source & $\begin{array}{c}\text { Type III } \\
\text { Sum of } \\
\text { Squares }\end{array}$ & df & $\begin{array}{c}\text { Mean } \\
\text { Square }\end{array}$ & \multicolumn{1}{c|}{ F } & \multicolumn{1}{c|}{ Sig. } & $\begin{array}{c}\text { Partial Eta } \\
\text { Squared }\end{array}$ \\
\hline Corrected Model & $9422.557^{\mathrm{a}}$ & 5 & 1884.511 & 14.595 & .000 & .382 \\
Intercept & 1609.638 & 1 & 1609.638 & 12.466 & .001 & .096 \\
VAR00003 & 742.128 & 2 & 371.064 & 2.874 & .060 & .046 \\
VAR00001 & 2839.719 & 1 & 2839.719 & 21.993 & .000 & .157 \\
\hline
\end{tabular}


Tahun XI, No. 20, April 2015

\begin{tabular}{|l|r|r|r|r|r|r|}
\hline VAR00003* & 347.936 & 2 & 173.968 & 1.347 & .264 & .022 \\
VAR00001 & & & & & & \\
Error & 15236.314 & 118 & 129.121 & & & \\
Total & 659150.000 & 124 & & & & \\
Corrected Total & 24658.871 & 123 & & & & \\
\hline
\end{tabular}

a. $\mathrm{R}$ Squared $=.382$ (Adjusted R Squared $=.356$ )

Pada tabel tersebut VAR00003 * VAR00001 interaksi antara variable metode pembelajaran memiliki nilai Sig $0,264>\alpha(0,05) \rightarrow \mathrm{Ho}$ (VAR00003) dan hasil pre test (VAR00001)

diterima. Jadi dapat disimpulkan tidak ada

\section{ANALISIS COVARIAN}

Tabel 4.12

Descriptive Statistics

Dependent Variable:Post Test

\begin{tabular}{|l|r|r|r|}
\hline VAR00003 & & & \multicolumn{2}{|c|}{ Mean } & Std. Deviation & $\mathrm{N}$ \\
\hline STAD & 62.7381 & 14.23678 & 42 \\
Konvensional & 73.6364 & 12.82093 & 44 \\
& & & \\
\hline NHT & 78.8158 & 10.16314 & 38 \\
Total & 71.5323 & 14.15905 & 124 \\
\hline
\end{tabular}

Pada tabel di atas dapat jelaskan bahwa rata-rata hasil belajar pada pembelajaran NHT menduduki peringkat pertama sebesar 78.82, kemudian peringkat kedua pembelajaran konvesional sebesar 73.64 dan peringkat ketiga pembelajaran STAD sebesar 62.74.

Tabel 4.13

Levene's Test of Equality of Error Variances ${ }^{a}$

Dependent Variable:Post Test

\begin{tabular}{|c|c|c|c|}
\hline $\mathrm{F}$ & df1 & df2 & Sig. \\
\hline 1.702 & 2 & 121 & .187 \\
\hline
\end{tabular}

Tests the null hypothesis that the error variance of the dependent variable is equal across groups.

a. Design: Intercept + VAR00001 + VAR00003

Nilai Sig 0,187> $\alpha(0,05)$, maka Ho diterima. Jadi varian antar ketiga kelompok sama. 
Tabel 4.14

Tests of Between-Subjects Effects

Dependent Variable:Post Test

\begin{tabular}{|l|r|r|r|r|r|r|}
\hline Source & $\begin{array}{c}\text { Type III Sum } \\
\text { of Squares }\end{array}$ & \multicolumn{1}{c|}{ df } & \multicolumn{1}{c|}{$\begin{array}{c}\text { Mean } \\
\text { Square }\end{array}$} & \multicolumn{1}{c|}{ F } & \multicolumn{1}{c|}{ Sig. } & \multicolumn{1}{c|}{$\begin{array}{c}\text { Partial Eta } \\
\text { Squared }\end{array}$} \\
\hline Corrected & $9074.621^{\mathrm{a}}$ & 3 & 3024.874 & 23.292 & .000 & .368 \\
Model & & & & & & .080 \\
Intercept & 1354.402 & 1 & 1354.402 & 10.429 & .002 & .000 \\
VAR00001 & 3615.761 & 1 & 3615.761 & 27.842 & .000 & .246 \\
VAR00003 & 5082.002 & 2 & 2541.001 & 19.566 & .000 & \\
Error & 15584.250 & 120 & 129.869 & & & \\
Total & 659150.000 & 124 & & & & \\
Corrected & 24658.871 & 123 & & & & \\
Total & & & & & & \\
\hline
\end{tabular}

a. R Squared $=.368$ (Adjusted R Squared $=.352$ )

Pada tabel Tests of Between-Subjects Effects ini nilai Sig $0.00<\alpha(0,05)$, maka Ho ditolak. Jadi dapat disimpulkan ada perbedaan hasil belajar antara mahasiswa yang mengikuti metode pembelajaran STAD, konvensional dan NHT.

Tabel 4.15

Parameter Estimates

Dependent Variable:Post Test

\begin{tabular}{|c|c|c|c|c|c|c|c|}
\hline \multirow[t]{2}{*}{ Parameter } & \multirow[b]{2}{*}{ B } & \multirow[b]{2}{*}{$\begin{array}{l}\text { Std. } \\
\text { Error }\end{array}$} & \multirow[b]{2}{*}{$\mathrm{t}$} & \multirow[b]{2}{*}{ Sig. } & \multicolumn{2}{|c|}{ 95\% Confidence Interval } & \multirow[b]{2}{*}{$\begin{array}{l}\text { Partial Eta } \\
\text { Squared }\end{array}$} \\
\hline & & & & & $\begin{array}{l}\text { Lower } \\
\text { Bound }\end{array}$ & $\begin{array}{l}\text { Upper } \\
\text { Bound }\end{array}$ & \\
\hline Intercept & 33.186 & 8.843 & 3.753 & .000 & 15.677 & 50.694 & .105 \\
\hline VAR00001 & .915 & .173 & 5.277 & .000 & .572 & 1.258 & .188 \\
\hline $\begin{array}{l}{[\text { VAR00003 = }} \\
1.00]\end{array}$ & -14.782 & 2.563 & -5.767 & .000 & -19.857 & -9.707 & .217 \\
\hline $\begin{array}{l}{[\mathrm{VAR} 00003=} \\
2.00] \\
{[\mathrm{VAR} 00003=} \\
3.00]\end{array}$ & $\begin{array}{r}-2.700 \\
0^{\mathrm{a}}\end{array}$ & 2.567 & -1.052 & .295 & -7.783 & 2.382 & .009 \\
\hline
\end{tabular}

Pada tabel tersebut menujukkan peserta yang dikenai metode pembelajaran STAD (Nilai B $=-14,782$ ) lebih rendah 14,782 pencapaian hasil belajarnya dibandingkan peserta yang dikenai metode pembelajaran Konvensional. Hal ini dikuatkan dengan nilai Sig $0,000<\alpha(0,05)$, Ho ditolak. Jadi ada pengaruh pemberian metode pembelajaran terhadap pencapaian hasil belajar.

\section{SIMPULAN}

Dalam penelitian ini terdapat perbedaan hasil belajar antara pembelajaran
STAD (Kelas A), pembelajaran konvensional (Kelas B) dan NHT (Kelas D). Meski rata-rata kelas pada pembelajaran NHT lebih tinggi tidak berarti kelas yang menggunakan pembelajaran konvensional nilai paling rendah. Dari hasil penelitian rata-rata nilai kelas pada pembelajaran konvesional lebih baik daripada rata-rata kelas pada pembelajaran STAD. 


\section{DAFTAR PUSTAKA}

Arikunto, S. (2005). Dasar-dasar Evaluasi Pendidikan. Jakarta: Depdikbud

Isjoni. 2007. Cooperative Learning. Bandung: Al Fabeta.

Muslimin, dkk. 2000. Pembelajaran Kooperatif. Edisi Pertama. Surabaya: Unesa University Press.

Muslimin, dkk. 2005. Pembelajaran Kooperatif. Edisi Kedua. Surabaya: Unesa University Press.

Nur, Muhamad. 2005. Pembelajaran Kooperatif. Surabaya: LPMP Jawa Timur.

Nur, M. dan Wikandari, R.P 2000. Pengajaran Berpusat Kepada Siswa dan Pendekatan Konstruktivis Dalam Pengajaran. Edisi ke-3 Surabaya: Pusat Sains dan Matematika Sekolah. UNESA Surabaya.

Sanjaya, W. 2007. Kajian Kurikulum Pembelajaran. Bandung: Sekolah Pascasarjana UPI.

Slavin, R. 1995. Cooperative Learning Theory, Reascerh and Practice. Second Edition. Boston: Allyn and Bacon.

Sugiyono. 2008. Statistik untuk Penelitian. Bandung: Alfabeta.

Wonda, Hiwa. 2009. Penerapan Model Pemebelajaran terpadu Tipe Connected dalam Pembelajaran IPS di $S D$. Makalah Komprehensif. Unesa. 